\title{
BORDADOS E BAILADOS
}

\section{Coristas e o Imaginário Moderno ${ }^{1}$}

Vera Collaço ${ }^{2}$

Laura Silvana Ribeiro Cascaes ${ }^{3}$

\begin{abstract}
RESUMO: Este artigo aborda as influências do imaginário moderno incorporado e projetado através do corpo que dança junto ao Teatro de Revista carioca, nos bailados da década de 1920, destacando aspectos relativos às mudanças e conquistas de direitos políticos e sociais das coristas. Para tal, pauta-se no método da História Cultural, tendo como procedimento metodológico estudos existentes sobre este gênero teatral e análise de fotografias das cenas dos espetáculos, esta última análise visa observar as mudanças e conquista de direitos referentes às coristas em relação à exposição estética do corpo.
\end{abstract}

PALAVRAS-CHAVE: Coristas, Imaginário, Dança.

Este artigo aborda as influências do imaginário moderno incorporado e projetado através do corpo que dança junto ao Teatro de Revista carioca, nos bailados da década de 1920, destacando aspectos relativos às mudanças e conquistas de direitos políticos e sociais das coristas ${ }^{4}$ (dançarinas). Para tal, pauta-se no método da História Cultural, tendo como procedimento metodológico estudos existentes sobre este gênero teatral e análise de fotografias das cenas dos espetáculos, esta última análise visa observar as mudanças e conquista de direitos referentes às coristas em relação à exposição estética do corpo.

Para tanto, será analisado um tipo de Teatro de Revista, a Revista da década de 1920, considerada por Salvyano Paiva (1991) e Neide Veneziano (1996) como sendo a Revista Clássica, aquela que não é mais a de Ano, mas que ainda não perdeu totalmente o contato com o texto, ou seja, que ainda apresenta um fio de enredo, mesmo que de forma muito tênue. Para desenvolver este trabalho apresento inicialmente uma breve

\footnotetext{
${ }^{1}$ Projeto de pesquisa Queria Bordar Teu Nome- A Dança no Teatro de Revista - Mestrado em Teatro PPGT - CEART/UDESC

${ }^{2}$ Professora e orientadora do PPGT - Mestrado em Teatro - Departamento de Artes Cênicas

${ }^{3}$ Aluna regular do PPGT - Mestrado em Teatro/ CEART-UDESC.

${ }^{4}$ A construção de movimentos dançados, no Teatro de Revista, integrava dança e dramaturgia, refletindo-se os aspectos culturais da sociedade. Neste sentido, os dançarinos no Teatro Musicado aparecem dançando ritmos variados, nos números de dança e canto, inseridos nos chamados "quadros de fantasia". Estes dançarinos denominavam-se, até a década de 1920, de coristas e depois passaram a ser anunciados como girls e boys, numa assimilação nominal das revistas estrangeiras.
} 
contextualização do imaginário moderno para situar as influências incorporadas pela dança e projetadas através do corpo, com suas inovações em cena, para depois tratar as questões referentes aos bailados, as novas conquistas em relação aos direitos emergentes a estas instâncias.

Torna-se possível identificar o imaginário moderno através das metáforas impressas neste corpo que dançou no Teatro Musicado, haja vista, que este corpo serviu de suporte de narrativas simbólicas e significados culturais presentes na sociedade, sendo capaz de armazenar um cruzamento de informações presentificadas nele mesmo. Ao referir-se ao imaginário como uma das categorias que caracterizam a história cultural, Pesavento (2005:43) pontua que: "significa um sistema de idéias e imagens de representação coletiva que os homens, [a humanidade], em todas as épocas, construíram para si, dando sentido ao mundo".

O imaginário moderno delineava-se e afirmava-se de diversas formas e incorporouse na cena revisteira, podendo ser observado em vários elementos. O figurino, por exemplo, apresentava uma mulher que se desejava livre, ou pelo menos com mais direitos e mais dignidade e representava uma grande transformação em relação ao final do século XIX - onde as mulheres da elite, com seu vestuário, desenhavam uma postura rígida, movimentos contidos, vestidos muito pesados e espartilhos que encarceravam o movimento natural. Segundo Hanna (1999:197) nos anos posteriores isto desmorona "com as mudanças na educação feminina, na saúde e na oportunidade profissional”. No Teatro de Revista conquistam-se mudanças referentes a este corpo feminino que dança, inclusive um direito emergente, que reflete no palco o início do rompimento de algumas barreiras e tabus, junto à ruptura de usar um figurino com pernas de fora, de deixar o corpo à mostra para ser visto e apreciado. O texto revisteiro também reforçava estas mudanças, como demonstra a Revista É da Pontinha, de 1927, escrita por Djalma Nunes e Jerônimo Castilhos, que segundo Paiva (1991:280) possuía letra, possivelmente de Lamartine Babo, que satirizava em cena as inovações advindas com "A Mulher Moderna":

\author{
A mulher moderna \\ Não há quem não diga \\ Deixa ver a perna acima da liga \\ Mas fazendo isso \\ Com galanteria \\ Tem o seu feitiço \\ Como igual ninguém teria.
}


A dança moderna também rompe com questões relacionadas ao figurino, abandonando espartilhos, sapatilhas de ponta, dando espaço para o surgimento de um vestuário leve, de influência da vestimenta grega, pés no chão, fazendo novas proposições estéticas. Segundo Sucena (1988: 129 e 137) a visita de Isadora Duncan ao Rio de Janeiro ocorre no início do século XX, em 1916, e Loie Fuller, um pouco antes, em 1904 -. Ambas foram ilustres personalidades para o surgimento e consolidação da dança moderna, respectivamente, e servem para demonstrar o cruzamento de informações que ocorrem nesta época e que possivelmente influenciaram as coristas no corpo de baile do Teatro de Revistas. No século XX, a modernidade instaurou um novo vocabulário estético, junto à criação de um sistema de dança que refletiu o pensamento moderno, agregando elementos que unem o corpo às forças da natureza, colocam os pés no chão, valorizam a beleza e a perfeição das formas, a relação com a gravidade, movimentos de atração, repulsão, resistências e não resistências. (BARIL, 1987: 27).

Este vértice que converge informações inovadoras presentificadas no corpo das coristas, transcende o âmbito do palco, já que aparecem de forma pioneira em cena e passam gradativamente a atingir o contexto cultural da sociedade, ditando modas, comportamentos, idéias, enfim, construindo o imaginário moderno em relação ao corpo da mulher que de forma incipiente e elementar, na década de 1920, já assinala as grandes mudanças que se tornarão mais visíveis décadas depois, especialmente a partir de 1960, com a revolução feminina: o surgimento dos anticoncepcionais, do feminismo, entre outros.

Depois de 1920 o corpo no Teatro de Revista aparece mais exposto, insinuado, ganhando uma projeção pela via do sensual. A partir de então, a mulher amplia seu espaço na cena através das vedetes. E como afirma Bevilaqua (2002: 244), depois da visita das companhias de revistas européias: "O elemento feminino recebe uma supervalorização, até então impensada, assim como a fantasia e o luxo, que são o tempo inteiro exaltados". O texto já não é considerado central, outros elementos ganham relevância, tais quais: a música, a dança, o figurino, os esquetes. Paulatinamente abre-se um grande portal de possibilidades para mulheres ocuparem outros espaços, e de forma gradativa, participarem em outras instâncias políticas e sociais, não somente no espaço privado, mas cada vez mais no âmbito público.

Segundo Melo (2004: 36), as peças de teatro de Revista trazem um 
[...] conjunto de elementos que compunham aquilo que era visto como a modernidade [...] o que se pode notar, por exemplo, na perplexidade de muitos diante da mudança de sentidos da presença feminina no espaço público, ligada entre outros fatores a maior liberdade de movimento conquistado por mulheres da classe média e alta.

Estes elementos discursivos revelam indícios e vestígios do imaginário moderno e podem ser reconhecidos na cena revisteira em vários elementos, por exemplo, através da presença da dança do maxixe, bem como outras danças de salão: tangos, rancheiras, boleros, que ampliam a proximidade corporal, através de um bailado que envolve a parceria entre homem e mulher. Estas danças esbarravam em preconceitos, já que ambos os dançarinos se tornavam responsáveis pela execução dos passos e o diálogo corporal entre os dois situava o homem em parceria com a mulher na dança. Também significava novas conquistas de direitos e espaço pelas mulheres, que se atualizam em relação às influências da moda, de novas idéias, novos comportamentos, e tornam-se cada vez mais atuantes.

Os recursos de linguagem e elementos simbólicos do Teatro de Revista também dialogavam com o imaginário moderno. Dizer uma coisa e fazer pensar em outra, inclui um discurso subentendido e simbólico, expresso através das alusões. Projetava-se, assim, um imaginário influenciado pela modernidade, a partir destas transformações, muitas delas incorporadas nos bailados: modificações no figurino, pernas à mostra, jogo de sedução, elegância, sensualidade, afirmação de padrões coreográficos e demonstrações de que o universo feminino inaugurava a quebra de tabus, e começava a era da mulher moderna.

\section{Buquê de Flores}

Através da contextualização histórica do início da década de 1920, serão destacados de forma breve alguns acontecimentos, especialmente considerando a incidência sobre algumas questões referentes aos direitos políticos, sociais e culturais emergentes, que atingem as coristas do Teatro de Revista.

No ano de 1922 funda-se o Partido Comunista em Niterói. Isto demonstra que novas idéias políticas desabrochavam. Em 1922 comemora-se o centenário da independência, ocorre à fundação da primeira rádio e a Semana de Arte Moderna de 22. 
Estes acontecimentos trazem repercussões muito importantes especialmente no campo estético e político. O cinema, segundo Paiva (1991: 212) contribuiu para a desinibição das coristas. Segundo ele: “[...] o corpo feminino começava a ser tratado como objeto estético digno de observação e não mais como santuário indevassável de virtudes vitorianas e hipocrisia".

Na década de 1920 o Teatro de Revista amplia sua velocidade. O ritmo intensificase, a música e a dança ganham o espaço perdido pelo texto, começa uma guinada para o carnaval. Afirmam-se as revistas pré-carnavalescas. Segundo Chiaradia (1997:154) Paschoal Segreto foi um empresário do ramo do entretenimento e dono do Teatro São José entre outros, onde a Companhia de Burletas e Revistas era sua menina-dos-olhos, que por sua vez, até 1922, apresentava-se em três sessões diárias, sem descanso semanal, num trabalho de segunda a segunda. Muitos corpos eram exauridos - nas grandes "apoteoses corporais".

Dois anos depois da Fundação do Partido Comunista, em 1924, as coristas no Teatro de Revista, fazem uma crítica ao sistema econômico, e encaram o riso como subversão, propondo-se a lutar por melhores condições de trabalho. Isto porque, neste ano, várias associações de artistas foram criadas, o corpo de baile unido, funda a União das Coristas e luta por sua profissão. Segundo Gomes (2004:103), as coristas recebiam um salário de 200 mil réis, sendo que em 1921 um aluguel no Rio de Janeiro, variava nos bairros mais baratos - na zona portuária (informado pelo jornal do Brasil de dezembro de 1921) custava na base dos 80 mil, e uma saca de arroz valia 2 mil réis em 1920, isto é, a classe artística no geral enfrentava dificuldades, salvo os provenientes de uma classe econômica mais favorecida, ou que também desempenhavam outra profissão. De acordo com os novos "ditames" estéticos, as coristas dos bailados passaram a pertencer ao novo padrão de beleza da modernidade, em que o culto ao corpo esbelto reforça-se continuamente. Possivelmente as antigas três sessões diárias, também contribuíram para exaurir seus corpos, que, por consequiência tornou-os mais magro.

Este corpo nem tão disciplinado, nem tão dominado pelo sistema econômico, já que a classe artística foi paulatinamente lutando por seus direitos profissionais e se colocando próxima a política, negociando melhores condições de trabalho, especialmente na década de 1920, junto ao então deputado federal Getúlio Vargas, que em 1926, através da Lei Getúlio Vargas reconheceu a profissão destes artistas, garantiu "o pagamento do direito 
autoral e a sujeição das relações entre patrões e empregados teatrais ao Código Comercial". (GOMES, 2004: 105)

Mesmo com toda a luta por direitos e melhores condições de trabalho no Teatro de Revista, observados ao longo da década de 1920, tal como o reconhecimento em lei da profissão de artistas, isto não impediu que muitos deles acabassem, no final de suas vidas e carreiras, em condições precárias de existência, muitos na miséria, no esquecimento, sem a dignidade necessária para usufruir de uma velhice respeitada. Ainda assim, foram ilustres as coristas, que participaram e doaram sua força física, trabalho corporal e estético para ajudar a construir a cena revisteira e sempre serão reverenciadas, homenageadas e onde estiverem, ficarão na memória da história do teatro brasileiro.

\section{Referências:}

BARIL, J. La Danza Moderna. Barcelona: Paidós, 1987.

BEVILAQUA, Ana. Apoteoses Corporais: A Presença do Corpo na Cena Revisteira da Década de 20. Dissertação de Mestrado. UNIRIO, 2002.

CASCAES. Laura. Queria Bordar Teu Nome. O Texto da Dança no Teatro de Revista in Se a Moda Pega: O Teatro de Revista em Florianópolis 1920/1930. Florianópolis: UDESC/CEART, 2007.

CHIARADIA, Maria Filomena Vilela. A Companhia de Burletas do Teatro São José: a menina dos olhos de Paschoal Segreto. Dissertação de Mestrado. Unirio, 2002.

GOMES, Thiago de. O Espelho no Palco: identidades sociais e massificação da cultura no teatro de revista dos anos 1920. Campinas, S.P: Editora da UNICAMP, 2004.

HANNA, Judith Lynne. Dança, Sexo e Gênero. Rio de Janeiro: Rocco, 1999.

PAIVA, Salvyano Cavalcanti de. Viva o Rebolado: Vida e Morte do Teatro de Revista no Brasil. R.J. Nova Fronteira, 1991. 
PESAVENTO, Sandra Jatahi. História \& História Cultural. Belo Horizonte: Autêntica, 2003.

SUCENA, Eduardo. A Dança Teatral no Brasil. R.J. Fundação Nacional de Artes Cênicas, 1988.

VENEZIANO, Neyde. O Teatro de Revista no Brasil: Dramaturgia e Convenções. Campinas: São Paulo: Pontes: UNICAMP, 1991.

Não Adianta Chorar: Teatro de Revista Brasileiro... Oba! Campinas: São Paulo: UNICAMP, 1996. 